\title{
Philosophiques
}

\section{Index du volume 27}

Volume 27, numéro 2, automne 2000

URI : https://id.erudit.org/iderudit/004934ar

DOI : https://doi.org/10.7202/004934ar

Aller au sommaire du numéro

Éditeur(s)

Société de philosophie du Québec

ISSN

0316-2923 (imprimé)

1492-1391 (numérique)

Découvrir la revue

Citer ce document

(2000). Index du volume 27. Philosophiques, 27(2), 465-466.

https://doi.org/10.7202/004934ar

Ce document est protégé par la loi sur le droit d'auteur. L'utilisation des services d'Érudit (y compris la reproduction) est assujettie à sa politique d'utilisation que vous pouvez consulter en ligne.

https://apropos.erudit.org/fr/usagers/politique-dutilisation/
Cet article est diffusé et préservé par Érudit.

Érudit est un consortium interuniversitaire sans but lucratif composé de l’Université de Montréal, l'Université Laval et l'Université du Québec à Montréal. Il a pour mission la promotion et la valorisation de la recherche. https://www.erudit.org/fr/ 


\section{Index}

Volume 27-2000

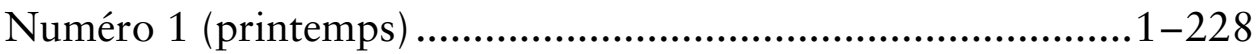

Numéro 2 (automne) …………………………...............229-462

\section{Articles}

Amselek, Paul, La science et le problème de la liberté humaine. ........ 403

Audureau, Eric, Les objets de la logique classique peuvent-ils

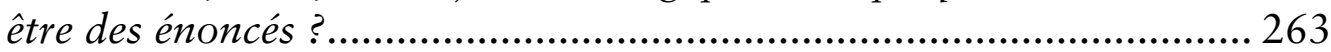

Bernier, Paul, Fonctionnalisme et similarité phénoménale ................... 99

Bernier, Paul, Introduction ............................................................. 3

BRANDOM, Robert B., Quelques thèmes pragmatistes

dans l'idéalisme de Hegel

Courtois, Stéphane, Habermas et la question du nationalisme :

le cas du Québec.

Dokic, Jérôme, Qui a peur des qualia corporels ?................................ 77

GARRETT, Brian, Héritabilité causale et propriétés émergentes. .......... 139

Jacob, Pierre, Ce que pense un individu peut-il

expliquer ce qu'il fait?

KIM, JAEGWON, L'émergence, les modèles de réduction

et le mental.

Kistler, Max, Réduction fonctionnelle et réduction logique.

LENOIR, NORBERT, Un problème de la légitimité politique dans la pensée de Rousseau.

Mclaughlin, Brian, Herméneutique cosmique.

Perru, Olivier, Pour une épistémologie du concept d'association chez Emile Durkheim et chez Max Weber.

Pettit, Philip, Le non-conséquentialisme et l'universalisabilité.

POIRIER, PIERre, L'empire contre-attaque :

le retour de la réduction psychophysique.

Proust, JoËlle, Les conditions de la connaissance de soi. 
Smith, Michael, Quelques énigmes concernant le contrôle de soi.

\section{Études critiques}

GrILlo, ÉRIC, Martin Montminy, Les fondements empiriques de la

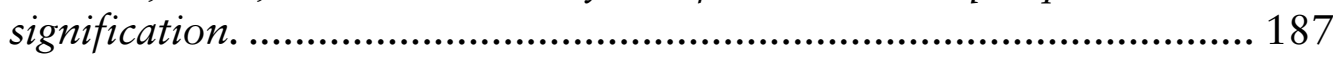

Montminy, Martin, Réponse à Éric Grillo........................................ 203

Ratté, Michel, Rainer Rochlitz, L'art au banc d'essai..................... 425

Rochlitz, Rainer, Réponse à Michel Ratté. .................................... 443

\section{Comptes rendus}

Badiou, Alain, Abrégé de métapolitique.

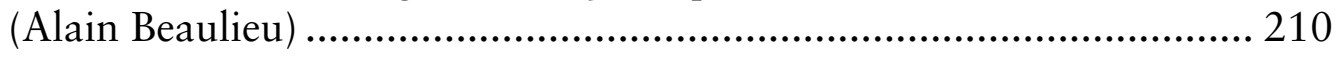

Badiou, Alain, Court traité d'ontologie transitoire.

(Alain Beaulieu) .................................................................................. 207

Badiou, Alain, Petit manuel d'inesthétique.

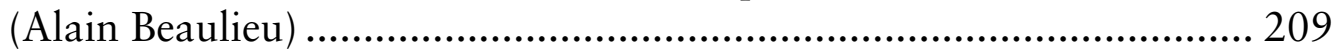

Benoist, Jocelyn, Brisart, Robert et English, Jacques, Liminaires phénoménologiques : recherches sur le développement de la théorie de la signification de Husserl.

(Guillaume Fréchette) ......................................................................... 219

Ellenberger, Henri F., Histoire de la découverte de l'inconscient.

(Marie-Andrée Charbonneau) ................................................................ 449

Kessler, Mathieu, L'esthétique de Nietzsche.

(Christine Daigle)...

Klibansky, Raymond et Boulad-Ayoub, Josiane, La pensée philosophique d'expression française au Canada. (éd.)

(Charles Larmore)........................................................................... 456

Lamy, Bernard, La Rhétorique ou l'art de parler.

(Lucie Desjardins) ............................................................................ 216

OMnÈs, Roland, Philosophie de la science contemporaine.

(Yvon Gauthier). 